\title{
Treatment of COPD by clinical phenotypes: putting old evidence into clinical practice
}

\author{
Marc Miravitlles*, Juan José Soler-Cataluña\#, Myriam Calle ${ }^{\star}$ and Joan B. Soriano+
}

\begin{abstract}
The new Global Initiative for Chronic Obstructive Lung Disease update has moved the principles of treatment of stable chronic obstructive pulmonary disease (COPD) forward by including the concepts of symptoms and risks into the decision of therapy. However, no mention of the concept of clinical phenotypes is included. It is recognised that COPD is a very heterogeneous disease and not all patients respond to all drugs available for treatment. The identification of responders to therapies is crucial in chronic diseases to provide the most appropriate treatment and avoid unnecessary medications. The classically defined phenotypes of chronic bronchitis and emphysema, together with the newly described phenotypes of overlap COPD-asthma and frequent exacerbator, allow a simple classification of patients that share clinical characteristics and outcomes and, more importantly, similar responses to existing treatments.

These clinical phenotypes can help clinicians identify patients that respond to specific pharmacological interventions. For example, frequent exacerbators are the only subjects with an indication for anti-inflammatory treatment in COPD. Among them, those with chronic bronchitis are the only candidates to receive phosphodiesterase-4 inhibitors. Patients with overlap COPDasthma phenotype show an enhanced response to inhaled corticosteroids and infrequent exacerbators should only receive bronchodilators. These well-defined clinical phenotypes could potentially be incorporated into treatment guidelines.
\end{abstract}

\section{KEYWORDS: Chronic obstructive pulmonary disease, guidelines, phenotypes, treatment}

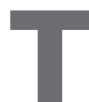

he history of the guidelines of treatment of chronic obstructive pulmonary disease (COPD) is an example of the simplification of a complex reality. The Venn diagram included in the 1995 American Thoracic Society (ATS) statement for the management of COPD reflected the complexity of the disease and its different clinical presentations [1]. However, the limited alternatives for pharmacological treatment at that time made it unnecessary to identify the different types of patients for clinical practice. The evolution of the concept of one-treatment-fits-all led to the selection of pharmacological treatment based almost exclusively on the severity of airflow obstruction introduced in the 2001 Global Initiative for Chronic Obstructive Lung Disease (GOLD) documents [2] and successive revisions up to the current 2013 documents [3]. The recent revision of the GOLD initiative has moved forward and changed the paradigm proposing a treatment directed by the intensity of symptoms (measured by the modified Medical Research Council dyspnoea scale and/or the COPD
Assessment Test) and the risk of poor outcomes (identified by the degree of airflow obstruction and/or the frequency of exacerbations) [3] in a three-dimensional evaluation, as previously suggested by LoPEz-CAMPOS [4]. This is clearly a significant improvement in considering the patient as a whole and not only by the degree of airflow obstruction; nevertheless, there is no mention of differential treatment based on clinical characteristics of patients in the document.

The past decade has seen an exponential increase in research in the field of COPD and new options for treatment of the disease have successfully been developed [5], together with new evidence about the use of old drugs in certain types of patients with COPD [6]. It has become increasingly evident that not all patients respond equally to all drugs (irrespective of the severity of symptoms and/or the level of risks), and the need to identify "responders" is crucial $[7,8]$. In this context, the concept of a clinical phenotype in COPD has emerged as "[...] those attributes

\section{AFFILIATIONS}

*Dept of Pneumology, Hospital Universitari Vall d'Hebron, Barcelona \#Unidad de Neumología, Servicio de Medicina Interna, Hospital de Requena, Valencia, "Servicio de Neumología, Hospital Clínico San Carlos, Madrid, and +Program of Epidemiology and Clinical Research, Fundación Caubet-CIMERA IIles Balears, Bunyola, Spain.

CORRESPONDENCE

M. Miravitlles

Pneumology Department. Hospital Universitari Vall d'Hebron P. Vall d'Hebron 119-129 08035 Barcelona

Spain

E-mail: marcm@separ.es

Received:

July 312012

Accepted after revision:

Oct 012012

First published online:

Oct 112012 
of the disease alone or in combination that describe the differences between individuals with COPD in relation to parameters that have clinical significance (symptoms, exacerbations, response to treatment, rate of progression disease, or death)" [9]. Therefore, the phenotype should be able to classify patients into subgroups with prognostic value and to determine the most appropriate therapy to achieve better results from a clinical standpoint.

\section{HOW MANY CLINICAL PHENOTYPES ARE THERE?}

Many previous studies have attempted to identify and quantify the prevalence of different phenotypes of COPD using populations of various sources, severities and particularities [10]. However, there is still no consensus on the number and definition of the different COPD phenotypes, being anywhere from two to 328 million (the estimated number of patients worldwide) [11]. However, there must be a compromise between the oversimplification of the term COPD as a definition that encompasses the entire spectrum of patients with incompletely reversible airflow obstruction largely caused by smoking, and the complexity of considering each patient individually as an orphan disease [12]. This intermediate step might arise from the identification and description of some phenotypes that not only have biological or epidemiological sense but also prognostic and therapeutic value, especially at the individual patient level.

\section{WHICH ARE THE RELEVANT CLINICAL PHENOTYPES?}

The old ATS Venn diagram included all the clinical types of patients with COPD and their overlaps [1]. If we want to define "clinically relevant" phenotypes we need to identify those phenotypes that, besides determining clinical outcomes, also characterise patients with a different or selective response to specific treatments and are prospectively validated. For example, from the seminal study by BuRrows et al. [13] it is clear that patients can present with predominant emphysema or chronic bronchitis, and this now has an impact on treatment since it has been demonstrated that only patients with chronic bronchitis (and exacerbations) respond to the new phosphodiesterase-4 $\left(\mathrm{PDE}_{4}\right)$ inhibitor roflumilast [5]. Therefore, identification of patients with the phenotype of frequent exacerbations and chronic bronchitis is relevant in clinical practice. Other phenotypes with clinical or therapeutic implications include the frequent exacerbator and overlap COPD-asthma.

The COPD exacerbator phenotype refers to patients with two or more exacerbations annually [14, 15]. This phenotype is based on clinical records and/or patient recall, and it has been shown that diagnosis based on patients reporting their history of exacerbations is reliable [16]. The COPD exacerbator phenotype implies a worse prognosis [17], underscores the importance of asking and recording the history of exacerbations in the clinical record, and identifies patients who may require anti-inflammatory treatment added to bronchodilators.

On the contrary, epidemiological studies of COPD incidence show that young asthmatics who smoke and develop not fully reversible airflow obstruction (i.e. COPD by definition) have a disease with different characteristics to those with chronic airflow obstruction but no history of asthma. In the first case, allergic rhinitis, bronchial hyperresponsiveness and the presence of wheezing, together with higher plasma concentrations of $\operatorname{IgE}$, are significantly more frequent, indicating that this is an overlap phenotype between asthma and COPD [18]. The overlap COPD-asthma phenotype has been defined as an incompletely reversible obstruction of airflow accompanied by symptoms or signals of increased reversibility of the obstruction $[19,20]$, or as the diagnosis of COPD in a patient with a history of previously diagnosed asthma before the age of 40 years [21]. These patients share characteristics of both diseases and represent a challenge in differential diagnosis, particularly in primary care [22]. The prevalence of this mixed phenotype is unknown, but there are different estimates of its importance in the context of COPD. This was reported in $13 \%$ of the COPDGene cohort [21]. SORIANO et al. [10] estimated that $\sim 23 \%$ of COPD patients aged $50-59$ years could have a mixed phenotype, with this percentage increasing with age. The relevance of this phenotype, already described in the Canadian [23] and Japanese [24] guidelines, is its enhanced response to inhaled corticosteroids [23-26].

These phenotypes identify patients with different responses to the available treatments and allow a more personalised approach to treatment, which is modulated according to COPD severity.

Other COPD phenotypes have been proposed, but their importance when directing treatment is not established. For example, the fast decliner is a patient with a greater than average fall in forced expiratory volume in $1 \mathrm{~s}$ (FEV1). A practical problem is that this phenotype is impossible to identify without close monitoring of lung function for at least 3 years [27], and no specific treatment for these patients is currently available. Similarly, an "inflammatory phenotype" has been described in patients with persistently elevated serum concentrations of inflammatory markers [28]. They are associated with poorer clinical outcomes but, as yet, no specific treatment has been identified for these patients. Current smokers may also represent a different phenotype with worse outcomes and poorer response to treatment, but we consider that current smokers must be identified across all phenotypes and intensive smoking cessation strategies must be adopted in these individuals. Moreover, a phenotype referred to as "systemic" or with significant comorbidity, being cardiovascular, metabolic or otherwise, has been identified [29]. However, we believe that comorbidity should always be considered as a feature in all patients and in all stages or grades that may accompany or complicate any of the clinical phenotypes. In addition to this, there is no specific or differential treatment for COPD with or without comorbidity (or comorbidities).

\section{HOW CAN WE TREAT COPD BASED ON CLINICAL PHENOTYPES?}

According to the different responses to pharmacological treatment, the recent Spanish guidelines for the treatment of COPD (Guía Española de la EPOC (GesEPOC)) have proposed four different phenotypes characterised by the combination of the classical types of emphysema, chronic bronchitis, exacerbators and patients with overlap COPD-asthma [30]. The proposed phenotypes in GesEPOC are as follows: 1) infrequent exacerbator with either chronic bronchitis or emphysema; 2) overlap COPD-asthma; 3) frequent exacerbator with 
predominant emphysema; and 4) frequent exacerbator with predominant chronic bronchitis [31].

Following the GOLD proposal, the frequent exacerbator is defined as having two or more exacerbations per year [3], based on, among others, the results of the ECLIPSE (Evaluation of COPD Longitudinally to Identify Predictive Surrogate Endpoints) study [14]. The COPD exacerbator frequently presents with chronic bronchitis, defined as the presence of productive cough or expectoration for $>3$ months per year and $>2$ consecutive years [32, 33]. Bronchial hypersecretion in COPD has been associated with increased airway inflammation and increased risk of bronchial colonisation and respiratory infection, which may explain why patients with chronic bronchitis have an increased frequency of exacerbations [32-34]. These patients may be treated with bronchodilators or inhaled corticosteroids, and respond to treatment with the $\mathrm{PDE}_{4}$ inhibitor roflumilast [5]. Selected cases of frequent exacerbators may respond to long-term treatment with macrolides [6] and quinolones (particularly if they produce dark sputum) [35], and, when inhaled corticosteroids cannot be used, mucolytics may be effective in reducing exacerbations [36-38].

When the frequent exacerbator does not present with chronic cough and sputum production and the typical clinical and radiological signs of emphysema can be identified, this establishes the exacerbator with an emphysema phenotype [39]. The basis of pharmacological treatment in these patients is long-acting bronchodilators and, in some cases, inhaled corticosteroids.

New studies have identified phenotypes of exacerbations including bacterial, viral, eosinophilic and pauci inflammatory. These phenotypes are quite stable and are related to the clinical phenotype in stable state [40,41]. For example, individuals with eosinophilic exacerbations usually have increased concentrations of peripheral eosinophils, even in stable state [40], and their exacerbations respond to systemic corticosteroids, which is in contrast to non-eosinophilic exacerbations that may have a poorer evolution with systemic corticosteroids compared to placebo [42]. It is tempting to associate infective exacerbations with the exacerbator with the chronic bronchitis phenotype, eosinophilic exacerbations with the overlap COPDasthma phenotype, and pauci inflammatory exacerbations with the exacerbator with an emphysema phenotype, but confirmatory studies are needed.

On the contrary, the infrequent exacerbator is defined as any patient experiencing less than two exacerbations per year. The importance of identifying this phenotype is that there is currently no anti-inflammatory treatment indicated or licensed for infrequent exacerbators, irrespective of having predominant emphysema or chronic bronchitis. The treatment of this phenotype is based on long-acting bronchodilators, alone or in combination, and the possible addition of theophyllines in the more severe cases [43].

Finally, the overlap COPD-asthma phenotype is associated with enhanced response to inhaled corticosteroids due to the predominance of eosinophilic bronchial inflammation [44, 45]. Therefore, these patients should be prescribed inhaled corticosteroids together with long-acting bronchodilators irrespective of the severity of the airflow obstruction, as recognised in some previous guidelines $[23,24]$. The Spanish guidelines have also recognised this phenotype [31] and a consensus document has been generated with diagnostic criteria to identify patients with overlap COPD-asthma [46]. Among these criteria, the most important are the history of previous asthma before the age of 40 years, the demonstration of eosinophilic inflammation in sputum or increased peripheral eosinophilia, and enhanced reversibility in airflow obstruction after the bronchodilator test. Due to the poor reproducibility of bronchodilator response, marked response $(>400 \mathrm{~mL}$ in FEV1) or at least two positive bronchodilator tests is required [46]. A simplified schematic of pharmacological treatment guided by clinical phenotypes is shown in figure 1.

This article focused on pharmacological treatments, but we should not forget that comprehensive treatment of COPD must include smoking cessation strategies, pulmonary rehabilitation, exercise, management of comorbidities and surgical options for selected patients.

\section{WHERE DO WE GO FROM HERE?}

It is clear that the approach to treatment according to clinical phenotypes represents a significant change in the management of COPD, from treatment focused on the severity of the airflow limitation to a more personalised approach directed by clinical features. Large pharmacological clinical trials have included unselected populations of patients with COPD and analysed the results as comparisons of mean values between treatment groups without considering the possibility of the existence of different populations of responders and nonresponders to a given drug [47]. New studies need to incorporate subgroup analysis of response by clinical characteristics [5, 6], or even be restricted to particular phenotypes to investigate the response

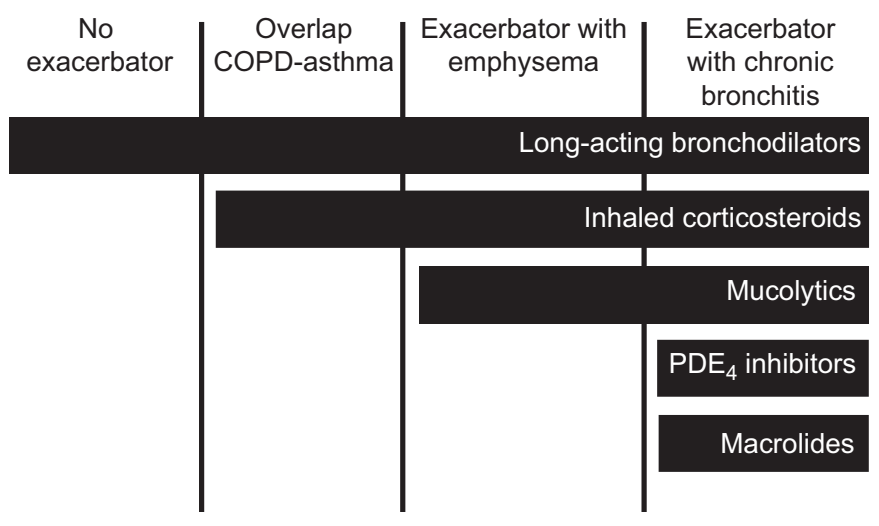

FIGURE 1. Proposal of pharmacological treatment of chronic obstructive pulmonary disease (COPD) according to clinical phenotypes. Bronchodilators are the basis of treatment of COPD irrespective of the clinical phenotype. Inhaled corticosteroids are indicated in frequent exacerbators and patients with the overlap COPD-asthma phenotype. Mucolytics can be used in frequent exacerbators, particularly if they have predominant chronic bronchitis and/or inhaled corticosteroids are not prescribed. Roflumilast is indicated in frequent exacerbators with chronic bronchitis. Finally, selected cases of patients with chronic bronchitis and frequent exacerbations, despite optimal therapy, may be candidates for treatment with long-term antibiotics under close follow-up in reference centres. The order of the bars does not represent the order of preference for treatment. $\mathrm{PDE}_{4}$ : phosphodiesterase-4. 
to therapy of a group of patients with common characteristics [48]. The results of these trials will help to personalise treatment for this complex disease. In the meantime we can use the classical phenotypes described here to easily identify subgroups of patients that will respond to different treatments. We believe that including these rapidly recognisable clinical phenotypes in management guidelines would help clinicians to select the most effective treatments for their patients. Nonetheless, this approach should be validated in future clinical studies.

\section{STATEMENT OF INTEREST}

Conflict of interest information can be found alongside the online version of this article at www.erj.ersjournals.com

\section{REFERENCES}

1 Standards for the diagnosis and care of patients with chronic obstructive pulmonary disease. American Thoracic Society. Am J Respir Crit Care Med 1995; 152: S77-S120.

2 Pawels RA, Buist AS, Calverley PMA, et al. Global strategy for the diagnosis, management, and prevention of chronic obstructive pulmonary disease. NHLBI/WHO Global Initiative for Chronic Obstructive Lung Disease (GOLD) workshop summary. Am J Respir Crit Care Med 2001; 163: 1256-1276.

3 Global Strategy for the Diagnosis, Management and Prevention of COPD, Global Initiative for Chronic Obstructive Lung Disease (GOLD) 2013. Available from: www.goldcopd.org.

4 Lopez-Campos JL. Treatment strategies in chronic obstructive pulmonary disease: a proposal for standardisation. Arch Bronconeumol 2010; 46: 617-620.

5 Rennard SI, Calverley PMA, Goehring UM, et al. Reduction of exacerbations by the $\mathrm{PDE}_{4}$ inhibitor roflumilast - the importance of defining different subsets of patients with COPD. Respir Res 2011; $12: 18$

6 Albert RK, Connett J, Biley WC, et al. Azithromycin for prevention of exacerbations of COPD. N Engl J Med 2011; 365: 689-698.

7 Miravitlles M. Arguments in favor of inhaled corticosteroids in COPD by phenotype instead of by severity. Arch Bronconeumol 2011; 47: 271-271.

8 Anderson D, MacNee W. Targeted treatment in COPD: a multisystem approach for a multi-system disease. Int J Chron Obst Pulm Dis 2009; 4: 321-335.

9 Han MK, Agusti A, Calverley PM, et al. Chronic obstructive pulmonary disease phenotypes: the future of COPD. Am J Respir Crit Care Med 2010; 182: 598-604.

10 Soriano JB, Davis KJ, Coleman B, et al. The proportional Venn diagram of obstructive lung disease: two approximations from the United States and the United Kingdom. Chest 2003; 124: 474-481.

11 Vos T, Flaxman AD, Naghavi M, et al. Years lived with disability (YLDs) for 1160 sequelae of 289 diseases and injuries 1990-2010: a systematic analysis for the Global Burden of Disease Study 2010. Lancet 2013; 380: 2163-2196.

12 Rennard SI, Vestbo J. The many "small COPDs": COPD should be an orphan disease. Chest 2008; 134: 623-627.

13 Burrows B, Fletcher CM, Heard BE, et al. The emphysematous and bronchial types of chronic airflow obstruction. Lancet 1966; 1 : 830-835.

14 Hurst JR, Vestbo J, Anzueto A, et al. Susceptibility to exacerbation in chronic obstructive pulmonary disease. N Engl J Med 2010; 363 $1128-1138$.

15 Soler Cataluña JJ, Martínez García MA, Catalán Serra P. The frequent exacerbator. A new phenotype in COPD? Hot Topics Respir Med 2011; 19: 7-12.
16 Quint JK, Donaldson GC, Hurst JR, et al. Predictive accuracy of patient-reported exacerbation frequency in COPD. Eur Respir J 2011; 37: 501-507.

17 Soler-Cataluña JJ, Martinez-García MA, Roman Sánchez P, et al. Severe acute exacerbations and mortality in patients with chronic obstructive pulmonary disease. Thorax 2005; 60: 925-931.

18 De Marco R, Accordini S, Cerveri I, et al. Incidence of chronic obstructive pulmonary disease in a cohort of young adults according to the presence of chronic cough and phlegm. Am J Respir Crit Care Med 2007; 175: 32-39.

19 Gibson PG, Simpson JL. The overlap syndrome of asthma and COPD: what are its features and how important is it? Thorax 2009; 64: 728-735.

20 Miravitlles M. The overlap syndrome between asthma and COPD: implications for management. Hot Topics Respir Med 2011; 16: 15-20.

21 Hardin M, Silverman EK, Barr RG, et al. The clinical features of the overlap between COPD and asthma. Respir Res 2011; 12: 127.

22 Miravitlles M, Andreu I, Romero Y, et al. Difficulties in differential diagnosis of COPD and asthma in primary care. $\mathrm{Br} J$ Gen Pract 2012; 62: e68-e75.

23 O'Donnell DE, Aaron S, Bourbeau J, et al. Canadian Thoracic Society recommendations for management of chronic obstructive pulmonary disease - 2007 update. Can Respir J 2007; 14: Suppl. B, 5B-32B.

24 Nagai A, Aizawa H, Aoshiba K, et al. Guidelines for the diagnosis and treatment of COPD. 3rd Edn. Tokyo, Japanese Respiratory Society, 2009

25 Brightling CE, McKenna S, Hardagon B, et al. Sputum eosinophilia and the short term response to inhaled mometasone in chronic obstructive pulmonary disease. Thorax 2005; 60: 193-198.

26 Leigh R, Pizzichini MMM, Morris MM, et al. Stable COPD: predicting benefit from high-dose inhaled corticosteroid treatment. Eur Respir J 2006; 27: 964-971.

27 Vestbo J, Edwards LD, Scanlon PD, et al. Changes in forced expiratory volume in 1 second over time in COPD. $N$ Engl J Med 2011; 365: 1184-1192.

28 Agustí A, Edwards LD, Rennard SI, et al. Persistent systemic inflammation is associated with poor clinical outcomes in COPD: a novel phenotype. PLoS One 2012; 7: e37483.

29 Garcia-Aymerich J, Gómez FP, Benet M, et al. Identification and prospective validation of clinically relevant chronic obstructive pulmonary disease (COPD) phenotypes. Thorax 2011; 66: 430-437.

30 Miravitlles M, Calle M, Soler-Cataluña JJ. Clinical phenotypes of COPD. Identification, definition and implications for guidelines. Arch Bronconeumol 2012; 48: 86-98.

31 Miravitlles M, Soler-Cataluña JJ, Calle M, et al. Spanish COPD guidelines (GesEPOC). Pharmacological treatment of stable COPD. Arch Bronconeumol 2012; 48: 247-257.

32 Montes de Oca M, Halbert RJ, López MV, et al. The chronic bronchitis phenotype in subjects with and without COPD: the PLATINO study. Eur Respir J 2012; 40: 28-36.

33 Miravitlles M. Cough and sputum production as risk factors for poor outcomes in patients with COPD. Respir Med 2011; 105: 11181128.

34 Kim V, Han MK, Vance GB, et al. The chronic bronchitic phenotype of COPD. An analysis of the COPDGene study. Chest 2011; 140: 626-633.

35 Sethi S, Jones PW, Theron MS, et al. Pulsed moxifloxacin for the prevention of exacerbations of chronic obstructive pulmonary disease: a randomized controlled trial. Respir Res 2010; 11: 10.

36 Poole PJ, Black PN. Mucolytic agents for chronic bronchitis or chronic obstructive pulmonary disease. Cochrane Database Syst Rev 2006; 3: CD001287.

37 Zheng JP, Kang J, Huang SG. Effect of carbocisteine on acute exacerbation of chronic obstructive pulmonary disease (PEACE 
Study): a randomized placebo-controlled study. Lancet 2008; 371: 2013-2018.

38 Decramer M, Rutten-van MM, Dekhuijzen PN, et al. Effects of $N$ acetylcysteine on outcomes in chronic obstructive pulmonary disease (Bronchitis Randomized on NAC Cost-Utility Study, BRONCUS): a randomized placebo-controlled trial. Lancet 2005; 365: 1552-1560.

39 Han MK, Kazerooni EA, Lynch DA, et al. Chronic obstructive pulmonary disease exacerbations in the COPD Gene Study: associated radiologic phenotypes. Radiology 2011; 261: 274-282.

40 Bafadhel M, McKenna S, Terry S, et al. Acute exacerbations of chronic obstructive pulmonary disease. Identification of biologic clusters and their biomarkers. Am J Respir Crit Care Med 2011; 184; 662-671.

41 Hurst J. Exacerbation phenotyping in chronic obstructive pulmonary disease. Am J Respir Crit Care Med 2011; 184: 625-626.

42 Bafadhel M, McKenna S, Terry S, et al. Blood eosinophils to direct corticosteroid treatment of exacerbations of chronic obstructive pulmonary disease. A randomized placebo-controlled trial. Am J Respir Crit Care Med 2012; 186: 48-55.
43 Ram FSF, Jardim JR, Atallah A, et al. Efficacy of theophylline in people with stable chronic obstructive pulmonary disease: a systematic review and meta-analysis. Respir Med 2005; 99: 135-144.

44 Papi A, Romagnoli M, Baraldo S, et al. Partial reversibility of airflow limitation and increased exhaled $\mathrm{NO}$ and sputum eosinophilia in chronic obstructive pulmonary disease. Am J Respir Crit Care Med 2000; 162: 1773-1777.

45 Siva R, Green RH, Brightling CE, et al. Eosinophilic airway inflammation and exacerbations of COPD: a randomised controlled trial. Eur Respir J 2007; 29: 906-913.

46 Soler-Cataluña JJ, Cosío B, Izquierdo JL, et al. Consensus document on the overlap phenotype COPD-asthma in COPD. Arch Bronconeumol 2012; 48: 331-337.

47 Calverley PMA, Anderson JA, Celli B, et al. Salmeterol and fluticasone propionate and survival in chronic obstructive pulmonary disease. N Engl J Med 2007; 356: 775-778.

48 Magnussen H, Bugnas B, van Noord J, et al. Improvements with tiotropium in COPD patients with concomitant asthma. Respir Med 2008; 102: 50-56. 